\title{
Cancellation of elective surgery: rates, reasons and effect on patient satisfaction
}

\author{
Wan Xian Koh, BSc \\ Rachel Phelan, MSc \\ Wilma M. Hopman, MA \\ Dale Engen, MD
}

This paper was presented at the 2018 Canadian Anesthesiologists' Society Annual Meeting in Montreal, Quebec.

Accepted April 30, 2020

\author{
Correspondence to: \\ D. Engen \\ Department of Anesthesiology and \\ Perioperative Medicine \\ Queen's University, Victory 2, \\ Kingston General Hospital site \\ Kingston Health Sciences Centre \\ Kingston ON K7L 2V7 \\ dale.engen@kingstonhsc.ca
}

DOI: $10.1503 /$ cjs.008119

\begin{abstract}
Background: The cancellation of elective surgeries is a major problem that increases wait times, exacerbates costs and can negatively affect patients, both psychologically and physically. Our objectives were to investigate the reasons for cancellations across specialties at a single centre, to compare these reasons with previous data from the same centre between 2005 and 2009 and to examine how cancellations affected patients' lives and views of the medical system in cases when the cancellations were potentially preventable.
\end{abstract}

Methods: Cancellation records of all elective surgeries scheduled between June 1, 2012, and Jan. 31, 2016, at a medium-sized, tertiary care, academic centre were retrospectively reviewed. We evaluated the rates and reasons for cancellation and interviewed a subset of patients whose surgery was cancelled for a potentially preventable reason (i.e., operating room running late, bed shortage, emergency case took place of scheduled surgery).

Results: Across 11 surgical specialties, 2933 of 20881 surgeries (14.0\%) were cancelled and of these, $2448(83.5 \%)$ were for administrative or structural reasons. Compared with the data collected previously for general, gynecological and urological procedures, cancellation rates increased from $8.1 \%$ to $11.8 \%$. Although patients reported inconvenience, they were generally satisfied with the availability and the quality of the health care they received.

Conclusion: Consistent with the previous study, our data suggest that most cancellations occur because of administrative or structural processes that are potentially preventable. Targeting these processes may help to reduce cancellations for elective surgeries and thereby improve economic efficiency and patient outcomes.

Contexte : L'annulation des chirurgies électives est un problème majeur qui allonge les temps d'attente, fait gonfler les coûts et peut affecter négativement les patients, tant psychologiquement que physiquement. Nos objectifs étaient de découvrir les raisons des annulations dans les diverses spécialités d'un seul centre, afin de comparer ces raisons à des données antérieures du même centre recueillies entre 2005 et 2009 et d'examiner en quoi les annulations affectent la vie des patients et leur perception du système médical dans les cas où les annulations auraient pu être évitées.

Méthodes : Les dossiers d'annulation de toutes les chirurgies électives entre le $1^{\text {er }}$ juin 2012 et le 31 janvier 2016 dans un centre hospitalier universitaire de soins tertiaires de taille moyenne ont été analysés de manière rétrospective. Nous avons évalué les taux d'annulation et les motifs, et interrogé un groupe de patients dont la chirurgie a été annulée pour des raisons potentiellement évitables (p. ex., retards au bloc opératoire, manque de lits, priorisation de cas plus urgents).

Résultats : Entre les 11 spécialités chirurgicales, 2933 des 20881 chirurgies (14,0\%) ont été annulées et parmi elles, $2448(83,5 \%)$ pour des raisons administratives ou structurelles. Comparativement aux données précédemment recueillies pour les interventions générales, gynécologiques et urologiques, les taux d'annulation ont augmenté de $8,1 \%$ à $11,8 \%$. Même si les patients ont déploré des inconvénients, ils se sont généralement déclarés satisfaits de la qualité des soins reçus et de leur accessibilité.

Conclusion : Comme lors de l'étude précédente, nos données suggèrent que les causes les plus fréquentes d'annulation sont liées à des marches à suivre administratives ou structurelles qui sont potentiellement évitables. Cibler ces marches à suivre pourrait contribuer à réduire le nombre d'annulations de chirurgies électives et améliorer de ce fait l'efficience économique et les résultats chez les patients. 


\section{$\mathbf{T}$} he cancellation of elective surgeries is a long-standing problem faced by many countries worldwide, including Canada. Operating rooms (ORs) are a major source of revenue and expenditure for many hospitals, and inefficiencies in their use often result in cancellations of elective surgeries. ${ }^{1}$ The cancellations then, in turn, exacerbate inefficiencies by disrupting the continuity of the workflow and affect provider morale across multiple departments. ${ }^{2}$ Cancellations also increase surgical wait times, increase costs and can have a major effect on patients and their families. ${ }^{3}$ Psychological effects include disappointment, frustration and dissatisfaction. ${ }^{3}$ In Canada's publicly funded health care system, patients often wait for months for surgery and may have rearranged their lives with caregivers and child care, taken time off of work or travelled long distances, only to have surgery cancelled at the last minute. Delays in medically necessary surgery may also worsen health outcomes. ${ }^{4,5}$

Cancellation rates reported in the literature are highly variable but can be as high as $39 \%$, with substantial differences depending on hospital type, national health care systems or policies, geographical region, patient population, providers and the perioperative management practices at that particular institution. ${ }^{2,3}$ Evidence suggests that most surgical cancellations are administrative in nature and are preventable. ${ }^{3}$ However, to prevent such cancellations, it is first essential to thoroughly understand the reasons for their occurrence. ${ }^{3}$ Previous work from our centre evaluated cancellation rates and reasons for cancellation across 3 surgical services (general surgery, gynecology and urology) and suggested that each cancellation should be treated as an adverse event, with documentation of the sequence of events that led to the cancellation. ${ }^{6}$

The objectives of this study are to evaluate the incidence of elective surgery cancellations at a single, tertiary care, academic centre across various surgical services, to identify the most common reasons for cancellation and to compare current data with previous data from the same centre. ${ }^{6}$ We also sought to interview a subset of patients for whom surgery was cancelled for potentially preventable administrative issues to determine how it affected their lives and views of the health care system.

\section{Methods}

We conducted this study at Kingston Health Sciences Centre (Kingston General Hospital site), a mediumsized (i.e., 471 beds), tertiary care academic teaching hospital in Kingston, Ontario. Using the hospital's patient management database, we retrospectively reviewed cancellation records of all elective surgeries that were scheduled to occur between June 1, 2012, and Jan. 31, 2016. We collected patient age, sex, American Society of Anesthesiologists (ASA) classification of physical status, estimated case duration, surgical procedure, scheduled surgical date, arrival time at the hospital's Same Day Admission Centre, time of cancellation and reason for cancellation. Eleven surgical services (i.e., cardiac surgery, dental surgery, general surgery, gynecology, neurosurgery, orthopedic surgery, otolaryngology, plastic surgery, thoracic surgery, urology and vascular surgery) were included in the study. Same-day cancellations were defined as any surgery listed on the OR schedule that did not occur on the day it was scheduled.

The patient management database contains 50 different cancellation codes. We reduced these 50 codes to 28 by regrouping similar codes (e.g., combining the codes for "no bed," "no intensive care unit bed," "no step-down bed" and "no recovery bed" into 1 code, "bed shortage"). We subsequently reclassified the 28 codes into 3 broad reasons for cancellation: medical (e.g., change in medical condition), patient-related (e.g., patient cancelled) and administrative or structural (e.g., bed shortage). Two investigators independently classified codes; any discrepancy was discussed and subsequently re-evaluated until an agreement was reached.

We compared the results from our study to those of a previous study at the same centre. The previous study included an analysis of cancellation rates for 3 surgical services (general surgery, urology and gynecology) between January 2005 and December 2009. ${ }^{6}$ Both studies were consistent in their definition of same-day cancellations, defined as any surgery listed on the OR schedule that did not occur the day it was scheduled. ${ }^{6}$ In the previous study by Leslie and colleagues, reasons for cancellation were classified into patient-related, process-related and structurerelated categories. ${ }^{6}$ Given the differences in classifications between the current and previous studies, we did not draw comparisons between categories. However, we were able to directly compare the frequencies of the most prevalent, potentially modifiable, reasons for cancellation in both studies, including "OR running late," "standby patient cancelled," "bed shortage" and "emergency case took place of scheduled surgery." Patients listed as "standby" were classified as such by the surgical service if the estimated time of booked cases was greater than the OR time available, as predicted by the patient management database or at the discretion of the surgeon.

One investigator (W. X. K.) also conducted a standardized telephone interview to evaluate the effect that the most common and potentially preventable cancellations had on patients' lives and their opinions of the health care system. We interviewed patients who were 18 years or older and who had a surgery cancelled between June 1 and Dec. 31, 2015, because of a common administrative or structural reason, namely "OR running late," "bed shortage" and "emergency case took place of scheduled surgery." We excluded standby patients from the interview, as they were scheduled for surgery later in the day with a warning that their surgery may be cancelled, which could 
have potentially biased their interview responses. However, we included these patients in the overall analysis, with "standby cancellation" treated as an independent reason for cancellation to allow comparison with the previous study from our centre. ${ }^{6}$ We chose the dates to ensure that patients were interviewed at least 1 year, but no more than 18 months, after their cancellation. We designed interview questions based on a review of the literature and previous work from the same centre. ${ }^{6}$ To our knowledge, there are no validated tools against which our interview tool could be validated. However, we circulated the interview among staff at our centre to ensure clarity and revised it accordingly before contacting patients for an interview. This process provided some degree of face and content validity. The first half of the interview documented patient cancellation details (e.g., demographic variables, surgical characteristics) using multiple choice questions. The remainder evaluated patient perspectives according to a 5 -point Likert scale.

\section{Statistical analysis}

We completed data analyses using Microsoft Excel and IBM SPSS version 24. Fisher exact tests were used for exploratory analyses to assess the effect of demographic variables and the surgical characteristics surrounding the cancellation on the patients' life and views of the medical system.

\section{Ethics approval}

This study was approved by the Queen's University Faculty of Health Sciences and Affiliated Teaching Hospital's Research Ethics Board (ANAE-286-15).

\section{Results}

The demographic characteristics for patients with surgical cancellations $(n=2933)$, those contacted for a telephone interview $(n=175)$, the respondents $(n=72)$ and nonrespondents $(n=103)$ are shown in Table 1. A total of 20881 elective surgeries across 11 surgical services were scheduled between June 1, 2012, and Jan. 31, 2016. Of these, $2993(14.0 \%)$ were cancelled on the day of surgery (Table 2). Cancellation rates varied according to surgical service. Neurosurgery and vascular surgery had the highest cancellation rates (20.8\% and $20.5 \%$, respectively). Gynecology and thoracic surgery had the lowest cancellation rates, both at $10.2 \%$ (Table 3 ).

When limited to the 3 surgical services (general, gynecology and urology) evaluated in the previous study, our cancellation rate was $11.8 \%$, higher than previously reported for the same centre (1544 cancellations of 19141 surgeries, $8.1 \%$ ) between January 2005 and December 2009. ${ }^{6}$ The cancellation rates observed in the current study were also higher for each surgical service individually (general, $13.5 \%$ v. $8.2 \%$; gynecology, $10.2 \%$ v. $6.8 \%$; urology, $12.1 \%$ v. $9.5 \%$ ).

In our study, $83.5 \%$ of the cancellations were for administrative or structural reasons, $8.8 \%$ were for medical reasons and $7.8 \%$ were because of patient-related factors (Table 2). Of the 2448 surgeries cancelled for administrative reasons, the most prevalent reasons were because the OR was running late $(24.9 \%)$, because a standby patient was cancelled (19.8\%), because of a bed shortage $(16.6 \%)$ and because an emergency case took the place of a scheduled surgery (11.5\%).

Although the rates of cancellations in general surgery, gynecology and urology caused by the OR running late (30.9\% v. $29.3 \%)$ and by cancelled standby patients (both at $17.2 \%$ ) remained fairly consistent across the previous and current studies, respectively, cancellations because of emergency cases decreased $(13.0 \%$ v. $6.3 \%)$ and cancellations because of bed shortages increased (7.2\% v. $13.4 \%)$. Interestingly, and probably for multiple reasons, the volume of surgical procedures in these surgical services has actually decreased since the previous study (320 per month v. 217 per month).

Of the 175 patients who met eligibility criteria and received a telephone call, 72 (41.1\%) completed the interview. The mean age of respondents was 58.4 (standard deviation [SD] 15.2 ) years; 33 respondents $(45.8 \%)$ were male (Table 1$)$. In total, 61 patients $(34.8 \%)$ were unreachable and $42(24.0 \%)$ refused to participate. About

Table 1. Demographic characteristics of 20881 surgeries scheduled between June 1, 2012, and Jan. 31, 2016

\begin{tabular}{|c|c|c|c|c|}
\hline Characteristic & $\begin{array}{l}\text { No. (\%) of cancelled surgeries* } \\
\qquad n=2933\end{array}$ & $\begin{array}{l}\text { No. (\%) of patients contacted } \\
\text { for interview } \\
n=175\end{array}$ & $\begin{array}{l}\text { No. (\%) of patients interviewed } \\
\qquad n=72\end{array}$ & $\begin{array}{l}\text { No. (\%) of nonrespondents } \dagger \\
\qquad n=103\end{array}$ \\
\hline Male & $1527(52.1)$ & $90(51.4)$ & 33 (45.8) & 57 (55.3) \\
\hline Age, yr, mean $\pm S D$ & $56.5 \pm 18.7$ & $57.2 \pm 17.3$ & $58.4 \pm 15.2$ & $60.7 \pm 16.0$ \\
\hline ASA 1-2 & $1650(56.2)$ & $33(18.8)$ & $41(56.9)$ & $49(47.6)$ \\
\hline ASA 3-4 & $891(30.4)$ & $125(71.4)$ & 22 (30.6) & $45(43.7)$ \\
\hline
\end{tabular}


Table 2 (part 1 of 2). Reasons for cancellation of 2933 surgeries scheduled between June 1, 2012 and Jan. 31, 2016

\begin{tabular}{|c|c|}
\hline Codes* & $\begin{array}{c}\text { No. (\%) of surgeries } \\
n=2933\end{array}$ \\
\hline Medical reasons & $257(8.8)$ \\
\hline Change in medical condition & $218(7.4)$ \\
\hline Change in medical condition after PSS & $159(5.4)$ \\
\hline Acute illness or condition $<24 \mathrm{~h}$ & $43(1.5)$ \\
\hline Change In medical condition $>24 \mathrm{~h}$ & $16(0.5)$ \\
\hline Insufficient workup & $19(0.6)$ \\
\hline Abnormal lab work & $16(0.5)$ \\
\hline Difficult anesthesia event & $1(0.0)$ \\
\hline Case aborted before anesthetic tarted & $1(0.0)$ \\
\hline Patient expired & $2(0.1)$ \\
\hline Patient-related reasons & $228(7.8)$ \\
\hline Patient refused procedure & $75(2.6)$ \\
\hline Patient unavailable & $56(1.9)$ \\
\hline Patient cancelled & $26(0.9)$ \\
\hline Patient did not show for surgery & $24(0.8)$ \\
\hline $\begin{array}{l}\text { Patient did not adhere to surgical } \\
\text { instructions }\end{array}$ & $47(1.6)$ \\
\hline Patient not NPO & $25(0.8)$ \\
\hline Patient noncompliant & $16(0.5)$ \\
\hline $\begin{array}{l}\text { Surgical instructions not followed } \\
\text { by patient }\end{array}$ & $6(0.2)$ \\
\hline Administrative or structural reasons & $2448(83.5)$ \\
\hline $\begin{array}{l}\text { Emergency case took place of scheduled } \\
\text { surgery }\end{array}$ & $282(9.6)$ \\
\hline Emergency case from other service & $37(1.3)$ \\
\hline Emergency case from same service & $245(8.4)$ \\
\hline OR running late & $610(20.8)$ \\
\hline Previous case ran over booked time & $263(9.0)$ \\
\hline Insufficient time remaining & $213(7.3)$ \\
\hline $\begin{array}{l}\text { Room running late because of computer } \\
\text { delay }\end{array}$ & $1(0.0)$ \\
\hline $\begin{array}{l}\text { Unexpected surgical complication from } \\
\text { previous case }\end{array}$ & $133(4.5)$ \\
\hline QBP target volumes met & $2(0.1)$ \\
\hline Code gridlock called & $94(3.2)$ \\
\hline PSS - surgery cancellled & $1(0.0)$ \\
\hline Incomplete presurgical screening & $8(0.3)$ \\
\hline Incorrectly booked — surgeon's office & $70(2.4)$ \\
\hline Standby patient cancelled & 486 (16.6) \\
\hline Case substitution & $247(8.4)$ \\
\hline Equipment or resource unavailable & $28(1.0)$ \\
\hline No platelets or blood available & $4(0.1)$ \\
\hline Case cart unavailable & $1(0.0)$ \\
\hline Imaging unavailable & $1(0.0)$ \\
\hline Equipment broken or unavailable & $22(0.8)$ \\
\hline No bed & $406(13.8)$ \\
\hline No ICU bed & $6(0.2)$ \\
\hline No bed & $371(12.6)$ \\
\hline No step-down bed & $24(0.8)$ \\
\hline $\begin{array}{l}\text { No recovery bed because of previous } \\
\text { case }\end{array}$ & $5(0.2)$ \\
\hline Staff unavailable & $82(2.8)$ \\
\hline Other staff unavailable & $4(0.1)$ \\
\hline
\end{tabular}

Table 2 (part 2 of 2). Reasons for cancellation of 2933 surgeries scheduled between June 1, 2012 and Jan. 31, 2016

\begin{tabular}{|c|c|}
\hline Codes* & $\begin{array}{l}\text { No. }(\%) \text { of surgeries } \\
\qquad n=2933\end{array}$ \\
\hline OR nursing staff unavailable & $24(0.8)$ \\
\hline Surgeon ill or not able to operate & $12(0.4)$ \\
\hline Surgeon unavailable & $27(0.9)$ \\
\hline Anesthesiologist late & $1(0.0)$ \\
\hline Anesthesiologist unavailable & $14(0.5)$ \\
\hline Surgeon's decision & $50(1.7)$ \\
\hline Environmental crisis cancellation & $29(1.0)$ \\
\hline Other reasons not listed & $3(0.1)$ \\
\hline Surgery no longer required & $29(1.0)$ \\
\hline Already done & $18(0.6)$ \\
\hline Already done & $14(0.5)$ \\
\hline $\begin{array}{l}\text { Already done as an emergency } \\
>24 \mathrm{~h}\end{array}$ & $3(0.1)$ \\
\hline $\begin{array}{l}\text { Already done as an emergency } \\
<24 \mathrm{~h}\end{array}$ & $1(0.0)$ \\
\hline Room availability & $3(0.3)$ \\
\hline \multicolumn{2}{|c|}{$\begin{array}{l}\text { ICU = intensive care unit; } N P O=\text { nothing by mouth (i.e., patient had recently consumed } \\
\text { food or liquids); } \mathrm{OR}=\text { operating room; } \mathrm{PSS}=\text { presurgical screening; } \mathrm{OBP}=\text { quality-based } \\
\text { procedure. }\end{array}$} \\
\hline \multicolumn{2}{|c|}{$\begin{array}{l}{ }^{*} \text { Codes are organized as } 50 \text { individual codes, regrouped into } 28 \text { groups and } 3 \text { overarching } \\
\text { categories. }\end{array}$} \\
\hline
\end{tabular}

half of the respondents (51.3\%) were cancelled after registration at the Same Day Admission Centre and 38.9\% reported having at least 1 surgery cancelled during the previous 5 years (Table 4). Overall, approximately half of the respondents (48.6\%) and their family/friends (55.6\%) missed at least 1 day of work and more than one-third of patients and their families travelled more than $80 \mathrm{~km}$ only to have the surgery cancelled $(34.4 \%$ and $33.3 \%$, respectively, Table 4).

Most respondents (62.5\%) reported that the cancellation caused them or their families moderate to extreme inconvenience (4-5 on Likert scale). Overall, however, patients were moderately satisfied (mean 3.2 [SD 1.5]) with the way their cancellation was handled by hospital staff and 29.2\% reported being very satisfied (5 on Likert scale) (Table 5).

Although most patients $(75.0 \%)$ agreed that fundamental changes should be implemented in the current health care system, respondents had varying opinions regarding the establishment of an alternative health care system (mean 2.8 [SD 1.3], Table 5). Twenty-seven respondents $(37.5 \%)$ were in favour of establishing an alternative health care system, 15 (20.8\%) were neutral and $30(41.7 \%)$ disagreed or strongly disagreed with there being a need for one. Overall, patients were satisfied with the availability (mean 3.8 [SD 1.3]) and quality (mean 3.8 [SD 1.1]) of affordable health care.

Age, sex, surgical procedure and administrative reasons for cancellation had no effect on patient reports regarding the cancellation or their attitude toward the health care system in general. However, patients classified as 


\begin{tabular}{|c|c|c|c|c|c|c|}
\hline \multirow[b]{2}{*}{ Surgical specialty } & \multirow[b]{2}{*}{$\begin{array}{l}\text { Estimated mean } \\
\text { duration (min) }\end{array}$} & \multirow{2}{*}{$\begin{array}{c}\text { No. }(\%) \text { of } \\
\text { scheduled } \\
\text { surgeries } \\
n=20881\end{array}$} & \multirow[b]{2}{*}{$\begin{array}{l}\text { No. }(\%) \\
\text { cancellations by } \\
\text { specialty }\end{array}$} & \multicolumn{3}{|c|}{ No. $(\%)$ of cancellations by specialty } \\
\hline & & & & $\begin{array}{l}\text { Cancelled for } \\
\text { medical reasons }\end{array}$ & $\begin{array}{c}\text { Cancelled for } \\
\text { patient-related reasons }\end{array}$ & $\begin{array}{l}\text { Cancelled for } \\
\text { administrative } \\
\text { reasons }\end{array}$ \\
\hline Cardiac surgery & 283 & $2008(9.6)$ & $315(15.7)$ & $12(3.8)$ & $11(3.5)$ & $292(92.7)$ \\
\hline Dental surgery & 86 & $150(0.7)$ & 26 (17.3) & $6(23.1)$ & $3(11.5)$ & $17(65.4)$ \\
\hline General surgery & 146 & $2916(14.0)$ & $395(13.5)$ & $46(11.6)$ & $19(4.8)$ & $330(83.5)$ \\
\hline Gynecology & 103 & $3600(17.2)$ & $366(10.2)$ & $26(7.1)$ & $41(11.2)$ & $299(81.7)$ \\
\hline Neurosurgery & 181 & $1271(6.1)$ & $265(20.8)$ & $17(6.4)$ & $11(4.2)$ & $237(89.4)$ \\
\hline Orthopedic surgery & 135 & $4783(22.9)$ & 707 (14.8) & $40(5.7)$ & $38(5.4)$ & $629(89.0)$ \\
\hline Otolaryngology & 119 & $410(2.0)$ & $44(10.7)$ & $6(13.6)$ & $7(15.9)$ & $31(70.5)$ \\
\hline Plastic surgery & 124 & $833(4.0)$ & $120(14.4)$ & $12(10.0)$ & $19(15.8)$ & $89(74.2)$ \\
\hline Thoracic surgery & 121 & $557(2.7)$ & $57(10.2)$ & $4(7.0)$ & $9(15.8)$ & $44(77.2)$ \\
\hline Urology & 104 & 3035 (14.5) & $368(12.1)$ & $58(15.8)$ & $50(13.6)$ & $260(70.7)$ \\
\hline Vascular surgery & 129 & $1318(6.3)$ & $270(20.5)$ & $30(11.1)$ & $20(7.4)$ & 220 (81.5) \\
\hline Total & - & 20881 & $2933(14.0)$ & $257(8.8)$ & $228(7.8)$ & 2448 (83.5) \\
\hline
\end{tabular}

Table 4. Details of cancellation among interviewed patients

\begin{tabular}{|c|c|}
\hline Interview question & $\begin{array}{l}\text { No. }(\%) \text { of } \\
\text { responses } \\
n=72^{*}\end{array}$ \\
\hline \multicolumn{2}{|l|}{ 1. When were you notified of the cancellation? } \\
\hline A. Before arrival at the hospital & $10(14)$ \\
\hline B. Before registration at the Same Day Admissions Centre & $25(35)$ \\
\hline C. After registration at the Same Day Admissions Centre & $37(51)$ \\
\hline D. I was not notified & $0(0)$ \\
\hline \multicolumn{2}{|l|}{ 2. How far did you travel to the hospital? } \\
\hline A. Less than $30 \mathrm{~km}$ & $35(57)$ \\
\hline B. $30 \mathrm{~km}$ to $80 \mathrm{~km}$ & $5(8)$ \\
\hline C. More than $80 \mathrm{~km}$ & $21(34)$ \\
\hline D. Out of province & $0(0)$ \\
\hline \multicolumn{2}{|l|}{ 3. How far did your loved ones travel to attend your surgery? } \\
\hline A. Less than $30 \mathrm{~km}$ & $32(53)$ \\
\hline B. $30 \mathrm{~km}$ to $80 \mathrm{~km}$ & $7(12)$ \\
\hline C. More than $80 \mathrm{~km}$ & $20(33)$ \\
\hline D. Out of province & $1(2)$ \\
\hline \multicolumn{2}{|l|}{$\begin{array}{l}\text { 4. How much time did you take off work for your surgery at } \\
\text { the time of the cancellation? }\end{array}$} \\
\hline A. Less than a week & $18(25)$ \\
\hline B. Between a week and a month & $8(11)$ \\
\hline C. More than a month & $9(13)$ \\
\hline D. None & $37(51)$ \\
\hline \multicolumn{2}{|l|}{$\begin{array}{l}\text { 5. How much time did your family member(s) or caregivers(s) } \\
\text { take off work to care for you at the time of the } \\
\text { cancellation? }\end{array}$} \\
\hline A. Less than a week & $32(44)$ \\
\hline B. Between a week and a month & $6(8)$ \\
\hline C. More than a month & $2(3)$ \\
\hline D. None & $32(44)$ \\
\hline \multicolumn{2}{|l|}{$\begin{array}{l}\text { 6. How many times have you had a surgery cancelled in the } \\
\text { past five years? }\end{array}$} \\
\hline A. Once & $44(61)$ \\
\hline B. More than once & 28 (39) \\
\hline${ }^{*}$ Total number of responses & \\
\hline
\end{tabular}

ASA level 3 or 4 were more often dissatisfied with how providers handled the cancellation $(p=0.02)$ and were less often satisfied with the availability of affordable health care $(p=0.02)$ than patients classified as ASA level 1 or 2 . The other factors that affected the patients' lives and views of the health care system included the financial impact associated with the distance travelled for surgeries $(p=0.03)$ and the time off work for patients $(p=0.03)$ and for their family and friends $(p=0.01)$. Patients whose surgeries had been cancelled more than once in the previous 5 years also reported a more negative view of the health care system $(p=0.04)$.

\section{Discussion}

Our overall cancellation rate was $14.0 \%$ across all 11 elective surgical services, which is well within the range of that reported in the literature for academic centres (i.e., 6\%-39\%). ${ }^{3}$ Cancellation rates attributed to administrative or structural factors $(83.5 \%)$, which are considered to be largely preventable, are also comparable to those reported in the literature $(87 \%),{ }^{3,5}$ but medical $(8.8 \%)$ and patient-related $(7.8 \%)$ cancellations account for a smaller proportion than previously reported. ${ }^{5,7,8}$ This may be explained, at least in part, by the long wait times for elective surgery in Canada, leading to greater patient adherence to the surgical schedule and preoperative instructions. ${ }^{9}$ Moreover, many centres have implemented presurgical screening clinics near the scheduled surgery date to medically optimize the patient, improve patient compliance with presurgical instructions and offset patient no-shows. ${ }^{10-13}$ This is supported by the fact that, of the 257 patients cancelled for medical reasons, $61.9 \%$ were attributed to changes in their medical condition after presurgical screening. 


\begin{tabular}{|c|c|c|c|c|c|c|}
\hline \multirow[b]{2}{*}{ Interview question } & \multicolumn{5}{|c|}{$\begin{array}{l}\text { No }(\%) \text { of responses* } \\
\qquad \begin{array}{l}n=72\end{array}\end{array}$} & \multirow[b]{2}{*}{ Mean \pm SD } \\
\hline & 1 & 2 & 3 & 4 & 5 & \\
\hline I was very satisfied with the way the cancellation was handled by the hospital staff. & $15(21)$ & $9(13)$ & $13(18)$ & $14(19)$ & $21(29)$ & $3.2 \pm 1.5$ \\
\hline $\begin{array}{l}\text { The cancellation had a significant financial impact on me (including transportation } \\
\text { costs, lodging costs, child care arrangements, loss of income, extended time off } \\
\text { work etc.). }\end{array}$ & $29(40)$ & $7(10)$ & $8(11)$ & $13(18)$ & $15(21)$ & $2.7 \pm 1.6$ \\
\hline The cancellation caused extreme inconvenience to myself and/or my family. & $16(22)$ & $4(6)$ & $7(10)$ & $15(21)$ & $30(42)$ & $3.5 \pm 1.6$ \\
\hline $\begin{array}{l}\text { The cancellation had a strong negative impact on my view of the Canadian health } \\
\text { care system. }\end{array}$ & $23(32)$ & $12(17)$ & $11(15)$ & $10(14)$ & $16(22)$ & $2.8 \pm 1.6$ \\
\hline The public should have access to an alternative health care system within Canada. & $18(25)$ & $12(17)$ & $15(21)$ & $21(29)$ & $6(8)$ & $2.8 \pm 1.3$ \\
\hline $\begin{array}{l}\text { There needs to be fundamental changes in the current Canadian health care } \\
\text { system. }\end{array}$ & $5(7)$ & $3(4)$ & $10(14)$ & $29(40)$ & $25(35)$ & $3.9 \pm 1.1$ \\
\hline I am satisfied with the availability of affordable health care in Canada. & $8(11)$ & $6(8)$ & $7(10)$ & $26(36)$ & $25(35)$ & $3.8 \pm 1.3$ \\
\hline I am satisfied with the quality of health care in Canada. & $3(4)$ & $8(11)$ & $8(11)$ & $35(49)$ & $18(25)$ & $3.8 \pm 1.1$ \\
\hline
\end{tabular}

Similar to other studies, ${ }^{2,7,8}$ we found that OR delays were responsible for a substantial number of cancellations, both in this study and the previous study from the same centre $(31.5 \%$ and $29.3 \%$, respectively). A closer look at the current data revealed that only $22 \%$ of the OR delays were caused by unexpected surgical complications; in contrast, $78 \%$ could be attributed to potentially modifiable logistical factors. One study attributed the main cause of OR delays to surgeons underestimating case duration or turnover time, particularly for shorter procedures. ${ }^{7}$ Furthermore, the surgeons who consistently underestimated surgical durations had significantly more cancellations. ${ }^{7}$

An insufficient number of beds also contributed to a substantial proportion of cancellations at our centre, and this problem appears to have worsened since the last report (7.2\% v. $13.4 \%)$. A perioperative simulation study from Canada identified bed availability as the bottleneck of our health care system. ${ }^{14}$ The 2017 report from the Fraser Institute found that Canada has the fewest acute care beds per capita of all 27 Organisation for Co-operation and Economic Development (OECD) countries with universal health care. ${ }^{9}$ According to a discrete event simulation study conducted at Toronto General Hospital, cancellations can be significantly reduced by adding just 2 beds to the surgical ward, although adding any more than 2 did not further improve efficiency. ${ }^{1}$

The prioritization of emergency cases is another major reason for cancellations of elective surgeries. In the current study, it accounted for $9.6 \%$ of the cancellations across all 11 surgical services. However, the decreased proportion of cancellations because of emergency cases since the previous study (13\% v. $6.3 \%)$, despite the fact that we still do not have a dedicated OR for emergencies, is encouraging. This suggests that there has been some improvement in the management of emergency cases. ${ }^{6}$
Despite the short notice of cancellations and the prolonged wait times for treatment, interviewed patients were generally satisfied with both the availability and quality of health care. Objectively, despite being the third most expensive health care system, Canada ranks below the OECD average with respect to the availability and accessibility of resources, while generally doing well on indicators for quality of health care. ${ }^{9}$ This apparent discrepancy between public perception and international performance rankings of our health care system has also been reported elsewhere. ${ }^{15}$ Our interview revealed a potential explanation for this discrepancy. We found that same-day cancellations $(51.3 \%)$ had only a minor effect on patients' negative view of the health care system (mean 2.8 [SD 1.6]), perhaps because the cancellations were handled by the hospital staff in a satisfactory manner (3.2 [SD 1.5], 48.6\% reported 4-5 on Likert scale). Our findings are consistent with those of the previous study conducted at this centre, which found that patients were modestly satisfied with the perioperative process despite the fact that approximately half of the cancellations occurred within an hour of the scheduled surgery. ${ }^{6}$

\section{Limitations}

Our study provides a report of elective surgical cancellation rates, as well as reasons for cancellation reported over time from an academic tertiary care centre. This is important because it serves as a comparison not only for this centre, but also for similar centres within Canada in terms of cancellation rates, reasons and potential starting points for mitigation strategies. However, being a single-centre study, these findings may not be generalizable to other institutions with different demographics and perioperative practices. It may be difficult to accurately 
compare our study with that done previously since each study evaluated different time periods. Leslie and colleagues ${ }^{6}$ collected data from 5 complete calendar years $(60 \mathrm{mo})$, whereas our study examined a 44 -month period that did not correspond to complete calendar years. We therefore could not account for changes in the coding of cancellations over time or for seasonal fluctuations in surgical volumes and cancellations.

Furthermore, given that data were retrospectively collected, we were unable to verify the reasons for cancellation or evaluate the precipitating factors. Only a small group of patients were contacted for an interview $(n=175)$, of which only $41 \%$ responded, potentially resulting in response bias. We chose an interview period of 12-18 months after cancellation to increase the likelihood that all patients had undergone their surgery in an attempt to reduce bias, but $28(38.9 \%)$ respondents had had more than 1 surgery cancelled within the previous 5 years, and the overall cancellation rate was $14.0 \%$, suggesting that responder bias may be present. As a result, the responses collected during the interview can be considered specific only to this small group and cannot be generalized to the entire population of patients with surgeries cancelled for administrative or structural reasons at our centre. Nevertheless, it is encouraging that the demographic distributions (i.e., sex, age and ASA classification) of the respondents and nonrespondents were similar to one another and these appear similar to that of all patients with cancelled surgeries (Table 1).

\section{Conclusion}

The cancellation rates observed in the current study are within the range reported for other academic centres. ${ }^{3}$ In addition, our results are consistent with the literature in that most cancellations occurred for administrative reasons (e.g., OR running late, emergency case took place of scheduled surgery, bed shortage) that are potentially preventable. ${ }^{3}$ Previous studies, including the one from our centre, have suggested that thorough documentation of cancellations (and the events leading up to them) is necessary before mitigation strategies can be identified. ${ }^{3,6}$ The observed increase in cancellation rates provides evidence that same-day elective surgery cancellations continue to impede timely care for patients at our centre. However, the small cohort that we interviewed was still satisfied with the quality and availability of health care, despite the fact that their surgery was cancelled for a potentially preventable reason, suggesting that the provider management of the cancellation can influence how it affects the patient, at least psychologically. Finally, the current data also suggest that potentially preventable administrative or structural issues may be a good starting point upon which to focus potential mitigation strategies.
Affiliations: From the Faculty of Medicine, University of British Columbia, Vancouver, BC (Koh); the Department of Anesthesiology and Perioperative Medicine, Queen's University, Kingston, Ont. (Phelan, Engen); and the Kingston General Health Research Institute, and Department of Public Health Sciences, Queen's University, Kingston, Ont. (Hopman).

Competing interests: None declared.

Content licence: This is an Open Access article distributed in accordance with the terms of the Creative Commons Attribution (CC BYNC-ND 4.0) licence, which permits use, distribution and reproduction in any medium, provided that the original publication is properly cited, the use is noncommercial (i.e., research or educational use), and no modifications or adaptations are made. See: https://creativecommons. org/licenses/by-nc-nd/4.0/.

Funding: This study was funded by the Department of Anesthesiology and Perioperative Medicine, Queen's University.

\section{References}

1. Azari-Rad S, Yontef AL, Aleman DM, et al. Reducing elective general surgery cancellations at a Canadian hospital. Can 7 Surg 2013;56:113-8.

2. Schuster M, Neumann C, Neumann K, et al. The effect of hospital size and surgical service on case cancellation in elective surgery: results from a prospective multicenter study. Anesth Analg 2011;113:578-85.

3. Al Talalwah N, McIltrot KH. Cancellation of surgeries: integrative review. 7 Perianesth Nurs 2019;34:86-96.

4. Magnusson H, Fellander-Tsai L, Hansson MG, et al. Cancellations of elective surgery may cause an inferior postoperative course: the 'invisible hand' of health-care prioritization? Clin Ethics 2011;6:27-31.

5. Caesar U, Karlsson J, Olsson L, et al. Incidence and root causes of cancellations for elective orthopaedic procedures: a single center experience of 17,625 consecutive cases. Patient Saf Surg 2014;8:24-30.

6. Leslie RJ, Beiko D, van Vlymen J, et al. Day of surgery cancellation rates in urology: Identification of modifiable factors. Can Urol Assoc 7 2013;7:167-73.

7. Schofield WN, Rubin GL, Piza M, et al. Cancellation of operations on the day of intended surgery at a major Australian referral hospital. Med 7 Aust 2005;182:612-5.

8. Dimitriadis PA, Iyer S, Evgeniou E. The challenge of cancellations on the day of surgery. Int 7 Surg 2013;11:1126-30.

9. Barua B, Hasan S, Timmermans I. Comparing performance of universal bealth care countries. Vancouver: Fraser Institute; 2017. Available: www.fraserinstitute.org/sites/default/files/comparing-performanceof-universal-health-care-countries-2017.pdf (accessed (2019 Apr. 1).

10. Kerridge R, Lee A, Latchford E, et al. The perioperative system: a new approach to managing elective surgery. Anaesth Intensive Care 1995;23:591-6.

11. Cantlay KL, Baker S, Parry A, et al. The impact of a consultant anaesthetist led pre-operative assessment clinic on patients undergoing major vascular surgery. Anaesthesia 2006;61:234-9.

12. Hovlid E, Bukve O, Haug K, et al. A new pathway for elective surgery to reduce cancellation rates. BMC Health Serv Res 2012;12:154-6.

13. Hovlid E, von Plessen C, Haug K, et al. Patient experiences with interventions to reduce surgery cancellations: a qualitative study. BMC Surg 2013;13:30.

14. Van Berkel PT, Blake JT. A comprehensive simulation for wait time reduction and capacity planning applied in general surgery. Health Care Manage Sci 2007;10:373-85.

15. Villeneuve M. The costs and performance of Canada's health system. Ottawa: Canadian Nurses Association; 2013. Available: www.cnaaiic.ca/ /media/cna/files/en/the_costs_performance_canadas_health_ system_e.pdf?la=en (accessed (2019 Apr. 1). 